\title{
EDITORIAL
}

\section{In This Issue: Practice, Research, and Reflection}

\author{
William R. Pbillips, MD, MPH
}

Ann Fam Med 2009;7:98-99. DOI: 10.1370/afm.972.

The Annals of Family Medicine provides a forum for the voices of all devoted to understanding and improving heath and health care. In this issue those voices include caring clinicians and patients, producers and consumers of research, and our editors and readers.

\section{PHYSICIAN PRACTICE}

Valderas and colleagues examined the content of office-based care by specialists in the United States and found that more than one-half of all visits are for ongoing follow-up and preventive services. ${ }^{1}$ Referrals accounted for only $30.4 \%$ of visits. The investigators developed a new taxonomy of office visits that accounts for types of patient, problem, and episode of care. Many of these specialist services could be provided in primary care settings (if adequate capacity was available in the United States). Such a shift could improve the use of resources, the focus of specialty expertise, and the coordination of patient care.

Pay-for-performance policies are being promoted in many countries to improve the efficiency and quality of care. McDonald and Roland interviewed primary care physicians in both the United Kingdom and California and uncovered unintended consequences at the practice level. ${ }^{2}$ In the United Kingdom, general practitioners worried about adverse effects on the office visit, with computer systems and data collection displacing direct patient communication. In the United States, they expressed resentment about the structure of the audit and payment systems, which sometimes distorted the process of care. The authors warn about "dysfunctional behaviors arising from the introduction of financial incentives and their likely consequences for patient care."

\section{MATERNITY CARE}

Family physicians have been important providers of maternity care in the United States, particularly in rural and underserved communities. Cohen and Coco report that the proportion of prenatal visits to family physicians in the United States declined nearly 50\% during the decade between 1995 and 2004. ${ }^{3}$ Using National Ambulatory Care Survey data, they document a decrease in percentage of prenatal visits to family physicians from $11.6 \%$ to $6.1 \%$. Family physicians provide higher proportions of visits for younger women and for those in rural areas and with poor insurance. Even in rural areas, however, the percentage of visits to family physicians fell from $38.6 \%$ to $12.9 \%$ over these years.

Looking at the same database, Coco also examined the content of prenatal visits and found that the care provided by family physicians was more comprehensive than that provided by obstetrician-gynecologists. ${ }^{4}$ Fully $17.6 \%$ of prenatal visits to family physicians dealt with more than obstetrical issues, whereas only $7.8 \%$ of visits to obstetrician-gynecologists did so.

Together, these studies suggest problems with access to maternity care services in the United States. They also raise serious questions about the role of family medicine in integrating care for the whole woman throughout the life cycle of her and her family.

\section{RESEARCH FOR QUALITY}

A working group of the North American Primary Care Research Group (NAPCRG), led by Solberg, challenges us to confront the quality chasm in primary care and take a new approach to improving process and outcomes. ${ }^{5}$ They call for changing the research paradigm from "translating research into practice" to "optimizing health and health care through research and quality improvement." We must bridge the current gap between clinical research and quality improvement. Doing so will require engaged scholarship and a new partnership among those who conduct, fund, publish, and implement research in primary care. By focusing on the problems of patients and patient care, we can work together to shorten the path from problems in practice to solutions in systems. 


\section{DOCTOR-PATIENT COMMUNICATION}

Shelley and colleagues explore barriers to patient-doctor communication about the use of traditional and alternative healing practices in a low income, Native American and Hispanic community. ${ }^{6}$ By using multiple approaches to hear the concerns of patients, clinicians, and clinic staff, they identify key practices and attitudes: acceptance and nonjudgment, initiation of communication, and concerns about safety and efficacy.

Patients with unexplained symptoms are a common challenge in primary care practice, and reassurance is an important part of their care. A team led by van Bokhoven in the Netherlands conducted a randomized clinical trial to test the notion that blood tests improve satisfaction. ${ }^{7}$ They found that watchful waiting resulted in patient satisfaction and anxiety equal to immediate blood testing. Communication was the most important predictor: talk is more helpful than testing, and listening is more powerful than the laboratory.

Egnew returns to reflect on the meaning of suffering and healing in our world of modern medicine. ${ }^{8}$ Healing is more than clinical services, prevention, and management of chronic disease. ${ }^{9-11}$ Physicians who can help patients transcend suffering are essential, he argues, to preserving medicine as a healing profession in the contemporary world. In the process, physicianshealers may "discover meaningful connections with patients that bring new and refreshing perspectives to their work."

Janet Townsend reflects in an essay on that last question in the patient visit: the one that so often opens Pandora's box of patient feelings and fears. ${ }^{12}$ She encourages us that "by opening Pandora's box, we make room for listening, for reflection, and for putting things into perspective, and with our gifts, we open doors for healing."

\section{ADVANCES IN PATIENT CARE AND RESEARCH METHODS}

Coleman and team review clinical trials and conclude that barley products improve serum total cholesterol, low-density lipoprotein cholesterol and triglycerides but not high-density lipoprotein cholesterol. ${ }^{13}$

Jerant and colleagues explore how personality factors may create important biases in response to surveys of primary care patients. ${ }^{14}$

\section{EDITOR REFLECTIONS}

In each issue of the Annals, our editorial team provides 2 regular features. "In This Issue" highlights articles and themes of special interest. "On TRACK" summarizes the online discussion on recent articles among our community of readers. We also publish a guest editorial to provide context and commentary on key findings reported in each issue. In this issue, we introduce a new series of editorials by Annals editor Kurt Stange. These will explore generalism: generalism in practice, in health care, in science, and in general. The first in this series is titled, "The Problem of Fragmentation and the Need for Integrative Solutions."15

\section{READER INSIGHTS}

As always, we ask you to share your reactions and insights. Please read and post comments on our online discussion, TRACK, at http://www.AnnFamMed.org.

\section{References}

1. Valderas JM, Starfield B, Forrest CB, Sibbald B, Roland M. Ambulatory care provided by office-based specialists in the United States. Ann Fam Med. 2009;7(2):104-111.

2. McDonald R, Roland M. Pay for performance in primary care in England and California: comparison of unintended consequences. Ann Fam Med. 2009;7(2):121-127.

3. Cohen D, Coco A. Declining trends in the provision of prenatal care visits by family physicians. Ann Fam Med. 2009;7(2):128-133.

4. Coco A. How often do physicians address other medical problems while providing prenatal care? Ann Fam Med. 2009;7(2):134-138.

5. Solberg LI, Elward KS, Phillips WR, et al. How can primary care cross the quality chasm? Ann Fam Med. 2009;7(2):164-169.

6. Shelley BM, Sussman AL, Williams RL, Segal A, Crabtree BF. 'They don't ask me so I don't tell them': patient-clinician communication about traditional, complementary, and alternative medicine. Ann Fam Med. 2009;7(2):139-147.

7. van Bokhoven MA, Koch $\mathrm{H}$, van der Weijden $\mathrm{T}$, et al. Influence of watchful waiting on satisfaction and anxiety among patients seeking care for unexplained complaints. Ann Fam Med. 2009;7(2):112-120.

8. Egnew TR. Suffering, meaning, and healing: challenges of contemporary medicine. Ann Fam Med. 2009;7(2):170-175.

9. Egnew TR. The meaning of healing: transcending suffering. Ann Fam Med. 2005;3(3):255-262.

10. Scott JG, Cohen D, DiCicco-Bloom B, Miller WL, Stange KC, Crabtree BF. Understanding healing relationships in primary care. Ann Fam Med. 2008;6(4):315-322.

11. Hsu C, Phillips WR, Sherman KJ, Hawkes R, Cherkin DC. Healing in primary care: a vision shared by patients, physicians, nurses, and clinical staff. Ann Fam Med. 2008;6(4):307-314.

12. Townsend JM. One last question: opening Pandora's box? Ann Fam Med. 2009;7(2):176-177.

13. Talati R, Baker WL, Pabilonia MS, White MC, Coleman CI. The effects of barley-derived soluble fiber on serum lipids. Ann Fam Med. 2009;7(2):157-163.

14. Jerant AF, Chapman BP, Duberstein P, Franks P. Is personality a key predictor of missing study data? An analysis from a RCT. Ann Fam Med. 2009;7(2):148-156.

15. Stange KS. The problem of fragmentation and the need for integrative solutions. Ann Fam Med. 2009;7(2):100-103. 